\title{
An R2R3-type myeloblastosis transcription factor MYB103 is involved in phosphorus remobilization
}

\author{
Fangwei Yu', Shenyun Wang ${ }^{1}$, Wei Zhang ${ }^{1}$, Hong Wang ${ }^{1}$, Li Yu' ${ }^{1}$ Zhangjun Fei ${ }^{2}$ and Jianbin Li ${ }^{1 *}$ (D
}

\begin{abstract}
The members of myeloblastosis transcription factor (MYB TF) family are involved in the regulation of biotic and abiotic stresses in plants. However, the role of MYB TF in phosphorus remobilization remains largely unexplored. In the present study, we show that an R2R3 type MYB transcription factor, MYB103, is involved in phosphorus (P) remobilization. MYB103 was remarkably induced by P deficiency in cabbage (Brassica oleracea var. capitata L.). As cabbage lacks the proper mutant for elucidating the mechanism of MYB103 in P deficiency, another member of the crucifer family, Arabidopsis thaliana was chosen for further study. The transcript of its homologue AtMYB103 was also elevated in response to P deficiency in A. thaliana, while disruption of AtMYB103 (myb103) exhibited increased sensitivity to $P$ deficiency, accompanied with decreased tissue biomass and soluble $P$ concentration. Furthermore, AtMYB103 was involved in the P reutilization from cell wall, as less P was released from the cell wall in myb103 than in wildtype, coinciding with the reduction of ethylene production. Taken together, our results uncover an important role of MYB103 in the P remobilization, presumably through ethylene signaling.
\end{abstract}

Keywords: Brassica oleracea var. capitata L., Arabidopsis thaliana, Cell wall, Ethylene, Phosphorus, MYB103

\section{Introduction}

Phosphorus $(\mathrm{P})$ is an important part of the adenylates and nucleotides, that is also involved in a wide range of cellular processes in all organisms (Lauer et al. 1989). The main source of $\mathrm{P}$ taken up by plants is inorganic phosphate $\left(\mathrm{H}_{2} \mathrm{PO}_{4}{ }^{-}\right.$and $\left.\mathrm{HPO}_{4}{ }^{2-}\right)$, but this form typically falls short to meet the requirement of most crops due to its active chemical property and microbial activity (Schachtman et al. 1998; Vance et al. 2003). Limited P availability in the soil results in higher input of $P$ fertilizers to ensure crop yield. However, this practice is neither sustainable nor environmental-friendly. Therefore, study on how plants utilize P will be helpful to breed new crop varieties with a higher P-acquisition and P-utilization efficiency.

\footnotetext{
* Correspondence: jbli@jaas.ac.cn

'Jiangsu Key Laboratory for Horticultural Crop Genetic Improvement, Institute of Vegetable Crops, Jiangsu Academy of Agricultural Sciences, Nanjing 210014, China

Full list of author information is available at the end of the article
}

Plants have evolved a wide range of sophisticated strategies to mount adaptive responses to P deficiency at multiple levels (Hammond et al. 2003; Lopez-Arredondo et al. 2014; Morcuende et al. 2007; Gutierrez-Alanis et al. 2018). In higher plants, excess $P$ is primarily stored in vacuole under $\mathrm{P}$ sufficiency and transported from vacuole under $\mathrm{P}$ deficiency. At the whole-plant level, stored $\mathrm{P}$ in older leaves is remobilized and transported to younger growing leaves and other active sinks under P deficiency (Mimura 1995). At physiological and biochemical levels, this strategy involves remodeling of root architecture, enhanced secretion of organic acids, and symbiosis with arbuscular mycorrhizal fungi (Lopez-Arredondo et al. 2014; Hans et al. 2006). At the molecular level, several transcription factors (TFs) have been implicated in the transcriptional reprogramming of plant responses to $\mathrm{P}$ deficiency (Baker et al. 2015; Franco-Zorrilla et al. 2004; Liang et al. 2014; Su et al. 2015; Wendrich et al. 2020). Recently, many efforts have been devoted to the elucidation of the role of

(c) The Author(s). 2020 Open Access This article is licensed under a Creative Commons Attribution 4.0 International License, which permits use, sharing, adaptation, distribution and reproduction in any medium or format, as long as you give appropriate credit to the original author(s) and the source, provide a link to the Creative Commons licence, and indicate if changes were made. The images or other third party material in this article are included in the article's Creative Commons licence, unless indicated otherwise in a credit line to the material. If material is not included in the article's Creative Commons licence and your intended use is not permitted by statutory regulation or exceeds the permitted use, you will need to obtain permission directly from the copyright holder. To view a copy of this licence, visit http://creativecommons.org/licenses/by/4.0/. 
the myeloblastosis transcription factors (MYB TFs) in $\mathrm{P}$ deficiency, which constitute one of the largest gene families in plants. For instance, AtPHR1 (Rubio et al. 2001) and AtMYB62 (Devaiah et al. 2009) are involved in the transcriptional response to $\mathrm{P}$ deficiency in Arabidopsis. In rice, an R2R3 MYB TF, OsMYB2P-1, plays a role in P starvation, as OsMYB2P-1 overexpression enhances tolerance to P starvation in rice (Dai et al. 2012). However, given that the MYB TFs are large in number and diverse in function (Dubos et al. 2010), our knowledge has yet to be expanded in terms of the roles of other MYB TFs in P nutrition.

Besides, several MYB TFs have been shown to couple with the hormone signaling network to confront environmental stresses. For instance, in mangosteen fruit, ethylene directly regulates $G m M Y B 10$ at the transcription level (Palapol et al. 2009). Overexpression of ethylene response factor TERF2 confers cold tolerance in rice through activating the expression of OsMYB (Tian et al. 2011). In fact, ethylene is not only involved in plant development such as fruit ripening (Schellingen et al. 2014), but also implicated in the cell wall $\mathrm{P}$ reutilization in P-deficient Arabidopsis and rice (Yu et al. 2016; Zhu et al. 2016). Here, we explored the role of MYB103, in P deficiency in Arabidopsis thaliana. Additionally, we examined the involvement of ethylene in remobilizing $\mathrm{P}$ from the cell wall through characterization of myb103, a loss-of-function mutant of MYB103.

\section{Materials and methods}

\section{Plant material and culture conditions}

A. thaliana wildtype (WT, Col-0) and the myb103 mutant in the Col-0 background (SALK_083678; obtained from the Arabidopsis Biological Resource Center, USA), cabbage (Brassica oleracea var. capitata L.) cultivar Sugan107 were used in this study. The MS nutrient solution contains the following macronutrients in $\mathrm{mM}$ : $\mathrm{Ca}\left(\mathrm{NO}_{3}\right)_{2}$ 4.0, $\mathrm{MgSO}_{4} 1, \mathrm{KNO}_{3} 6.0$ and $\mathrm{NH}_{4} \mathrm{H}_{2} \mathrm{PO}_{4}$ 0.1, and the following micronutrients in $\mu \mathrm{M}: \mathrm{CuSO}_{4} 0.5$, $\mathrm{MnSO}_{4} 1, \mathrm{H}_{3} \mathrm{BO}_{3} 12.5, \mathrm{ZnSO}_{4} 1, \mathrm{H}_{2} \mathrm{MoO}_{4} 0.1, \mathrm{NiSO}_{4}$ 0.1 and $\mathrm{Fe}(\mathrm{III})$-EDTA 50.

Seeds were sterilized in $75 \%$ ethanol (v/v) for $5 \mathrm{~min}$, and washed by sterilized water for three times. Then seeds were either grown on the $0.8 \%$ agar-solidified MS nutrient medium for 1 week before the petri dish assay, or grown on the sponge supplied with the MS nutrient solution for 6 weeks before the hydroponic assay. For the petri dish assay, uniform seedlings were selected and transferred onto solid MS nutrient medium with $(+\mathrm{P}$; complete medium as described above) or without $\mathrm{P}(-\mathrm{P}$; $0.1 \mathrm{mM} \mathrm{NH}_{4} \mathrm{H}_{2} \mathrm{PO}_{4}$ was replaced by $0.1 \mathrm{mM} \mathrm{NH} \mathrm{NH}_{3}$ ) for another week. The petri dishes were vertically placed in a growth chamber with a temperature of $23^{\circ} \mathrm{C} \pm 1{ }^{\circ} \mathrm{C}$, a light intensity of $140 \mu \mathrm{mol} \mathrm{m}^{-2} \mathrm{~s}^{-1}$ and a photoperiod of $16 \mathrm{~h}$ of light and $8 \mathrm{~h}$ of dark. For the hydroponic assay, uniform seedlings were selected and transplanted into MS nutrient solution with $(+\mathrm{P})$ or without $\mathrm{P}(-\mathrm{P})$ for another week. The solution was renewed every $3 \mathrm{~d}$.

\section{Determination of soluble $\mathrm{P}$ concentration}

Fresh weights of root and leaves of Arabidopsis were determined, followed by homogenization in liquid nitrogen with mortar and pestle. The finely ground tissue powder was used for determination of soluble $\mathrm{P}$ as previously described (Wang et al. 2018).

\section{Cell wall and pectin extraction}

Cell wall preparation was conducted as previously described (Zhong and Lauchli 1993). Briefly, finely ground samples were added with $8 \mathrm{~mL} \mathrm{75 \%} \mathrm{ethanol} \mathrm{(v/v)} \mathrm{and} \mathrm{incubated} \mathrm{at}$ $4^{\circ} \mathrm{C}$ for $20 \mathrm{~min}$. After centrifugation at $8000 \mathrm{rpm}$ for 15 min at $4{ }^{\circ} \mathrm{C}$, the pellet was sequentially washed with $8 \mathrm{~mL}$ acetone, $8 \mathrm{~mL}$ chloroform-methanol mixture $(1: 1, \mathrm{v} / \mathrm{v}), 8$ $\mathrm{mL}$ methanol, each for $20 \mathrm{~min}$ at $4{ }^{\circ} \mathrm{C}$. Cell wall materials were freeze dried, and kept at $4{ }^{\circ} \mathrm{C}$ for further use.

Pectin was extracted as previously described (Zhong and Lauchli 1993). The above cell wall materials were weighed, incubated with $1 \mathrm{~mL}$ distilled water for $1 \mathrm{~h}$ at $100^{\circ} \mathrm{C}$, followed by centrifugation at $12000 \mathrm{rpm}$ for 15 min to collect the supernatant. The pellet was then incubated with distilled water for $1 \mathrm{~h}$ at $100^{\circ} \mathrm{C}$ for another two times as described above, and the supernatants were combined as the pectin fraction.

\section{Measurement of pectin content}

Pectin content was measured as described (Blumenkrantz and Asboe-Hansen 1973). Firstly, $200 \mu \mathrm{L}$ pectin fraction was combined with $1 \mathrm{~mL} 12.5 \mathrm{mM} \mathrm{Na}_{2} \mathrm{~B}_{4} \mathrm{O}_{7} \cdot 10 \mathrm{H}_{2} \mathrm{O}$ (dissolved in $98 \% \mathrm{H}_{2} \mathrm{SO}_{4}$ ) in a $2 \mathrm{~mL}$ Eppendorf tube, followed by incubation at $100^{\circ} \mathrm{C}$ for $5 \mathrm{~min}$. After chilling, the above samples were mixed with $20 \mu \mathrm{L} 0.15 \%$ Mhydroxy-diphenyl (Sigma, Cat.: 26, 225-0) and kept at room temperature for $20 \mathrm{~min}$, followed by measurement of the absorbance at $520 \mathrm{~nm}$. Galacturonic acid (Sigma) was used as the standard.

\section{Measurement of $\mathrm{P}$ concentration in cell wall and pectin} Cell wall $\mathrm{P}$ concentration was determined as described (Zhu et al. 2015). Firstly, about $5 \mathrm{mg}$ cell wall material was weighed, and $1 \mathrm{~mL} 2 \mathrm{M} \mathrm{HCl}$ was added with occasional shaking for $72 \mathrm{~h}$. After centrifugation $(16,363 \mathrm{~g}$ for 15 $\mathrm{min}), 0.7 \mathrm{~mL}$ supernatant was collected and $4.3 \mathrm{~mL} \mathrm{HCl}$ $(2 \mathrm{M})$ was added for the P concentration measurement by inductively coupled plasma-mass spectrometry (ICP-MS).

Pectin P concentration was determined as described (Zhu et al. 2015). Firstly, $1.5 \mathrm{~mL}$ pectin fraction was combined with $3.5 \mathrm{~mL} \mathrm{HCl}(2 \mathrm{M})$, followed by measurement of the $\mathrm{P}$ concentration by ICP-MS. 
Quantitative real-time PCR (qRT-PCR) analysis

Tissue RNA was extracted using the RNAprep Pure Kit (TianGen, China). Total RNA was then reverse transcribed to cDNA using the PrimeScript $\mathrm{RT}^{\circ}$ reagent kit (Takara) following the manufacturer's procedure. For qRT-PCR, the reaction mixture contained SYBR Premix ExTaq $(5 \mu \mathrm{L}$; Takara), forward primer $(0.4 \mu \mathrm{L})$, revise primer $(0.4 \mu \mathrm{L})$, RNA-free water $(2.2 \mu \mathrm{L})$ and 5 -folddiluted cDNA template $(2 \mu \mathrm{L})$. Four replicates were used for each cDNA sample, and the relative quantification level of each gene was calculated using the $2^{-\Delta \Delta C T}$ method (Livak and Schmittgen 2001) and UBIQUITIN 10 as the internal reference. Primers used here were listed in Table S1.

\section{Detection of root ethylene production}

Measurement of root ethylene production was conducted as described (Wu et al. 2011). Roots were detached and then transferred to $6 \mathrm{~mL}$ glass vials. After adding $1 \mathrm{~mL}$ distilled water, the vials were immediately sealed in darkness for $3 \mathrm{~h}$ at $28^{\circ} \mathrm{C}$. The concentration of ethylene in the glass vials was then measured.

\section{Data analysis and statistics}

All experiments were independently conducted at least three times. Student's $t$ test was performed to compare two groups of data. For multiple comparisons, the data were analyzed by One-way ANOVA, followed by post hoc analysis with Duncan's multiple range test. Different letters indicate significant differences at $P<0.05$.

\section{Results}

\section{MYB103 is upregulated in response to $\mathrm{P}$ deficiency}

Firstly, qRT-PCR was conducted to investigate whether expression of MYB103 is responsive to $\mathrm{P}$ deficiency. After exposure to $\mathrm{P}$ deprivation for $7 \mathrm{~d}$, the relative expression of MYB103 was determined. In B. oleracea var. capitata L., the expression of MYB103 (BoMYB103) was dramatically increased in response to $\mathrm{P}$ deficiency (Fig. 1a). We are interested to see whether it is also true in any other member of crucifer family like A. thaliana. As expected, the expression of MYB103 (AtMYB103) was also increased under $\mathrm{P}$ deficiency, albeit to a lesser degree (Fig. 1b). The observation that $\mathrm{P}$ deficiency induces the expression of MYB103 in both $A$. thaliana and $B$. oleracea, albeit to different extents, can be suggestive of the possible involvement of MYB103 in responses to $\mathrm{P}$ deficiency. As cabbage lacks the proper mutant for elucidating the mechanism of MYB103 in P deficiency, the homologue of MYB103 in A. thaliana was chosen for further study.

\section{Disruption of MYB103 causes increased sensitivity to $P$ deficiency}

To further clarify the role of MYB103 in response to P deficiency, a T-DNA insertion line (SALK_083678) was selected for further study. The T-DNA was inserted into the third exon of AtMYB103 (Supplemental Figure 1A), thereby disrupting AtMYB103 expression in the homozygous line (Supplemental Figure 1B). One major symptom of $\mathrm{P}$ deficiency is the inhibition of root growth. After growth on P-deficient medium for $7 \mathrm{~d}$, the root length of WT was inhibited by approximately $15 \%$, whereas more dramatic inhibition (42\%) was observed in myb103 (Fig. 2a, b and c). In addition, myb103 exhibited decreased root biomass compared to WT (Fig. 2d), although no remarkable variations were observed in their shoot biomass (Fig. 2e). These results together indicate that the disruption of MYB103 resulted in increased sensitivity to $\mathrm{P}$ deficiency.

\section{Disruption of MYB103 impairs P remobilization}

The sensitivity to P deficiency in myb103 mutant was attributed to its lower levels of root and shoot soluble P

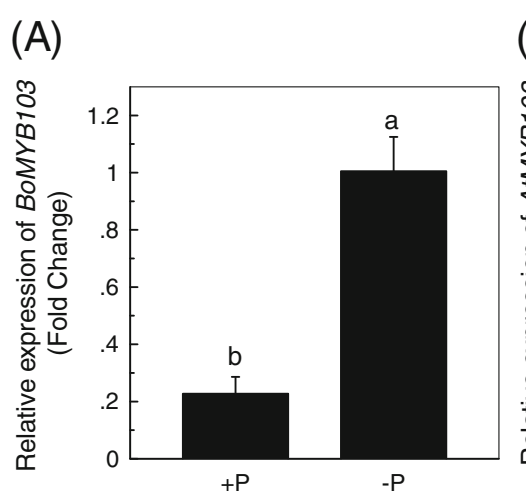

(B)

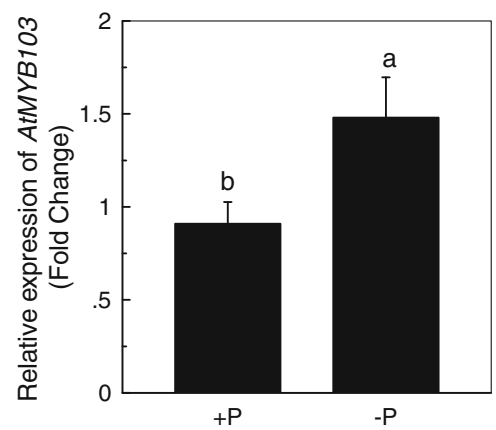

Fig. 1 Relative expression of MYB103 in response to P deficiency in Arabidopsis thaliana and Brassica oleracea. Seedlings were hydroponically treated with $+P$ or $-P$ solution for $7 \mathrm{~d}$, and the expression of MYB103 was measured in B. oleracea (a) and A. thaliana (b) respectively. Values are means $\pm S D, n=4$. Different letters on the bars indicate significant differences at $p<0.05$ 

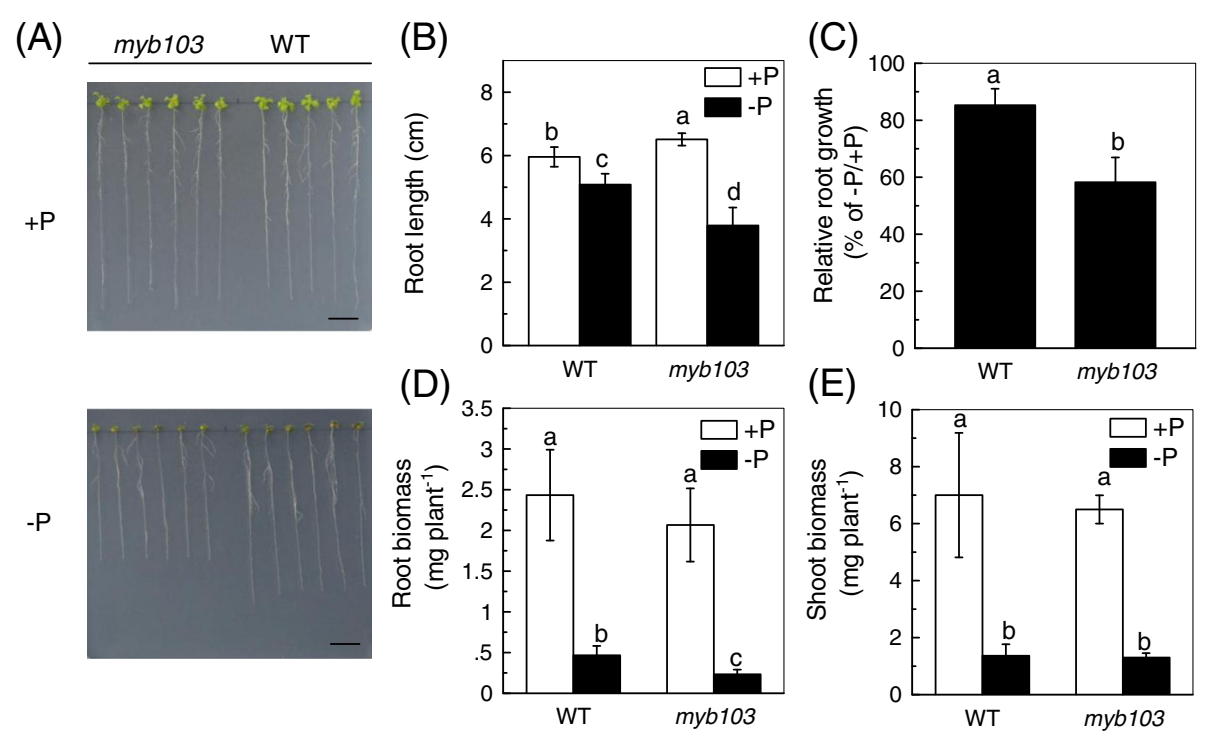

Fig. 2 Phenotype of myb103 mutant. Seeds of WT and myb103 were surface-sterilized and germinated on the complete nutrient medium, and seedlings with the root length of about $1 \mathrm{~cm}$ were transferred to the complete nutrient medium $(+P)$ or medium without $P(-P)$ for $7 \mathrm{~d}(\mathbf{a})$, and root length $(\mathbf{b})$, relative root growth $(\mathbf{c})$, ratio of root length in $+\mathrm{P}$ to root length in $-\mathrm{P})$, root biomass $(\mathbf{d})$ and shoot biomass (e) were measured. Scale $\mathrm{bar}=1 \mathrm{~cm}$. Values are means $\pm S D, n=4$. Different letters on the bars indicate significant differences at $p<0.05$

than WT (Fig. 3a and b), also, less P was translocated to the shoots (Fig. 3c), suggesting that MYB103 was involved in response to $\mathrm{P}$ deficiency. All the above results correlated well with the up-regulated expression of $\mathrm{P}$ deficiency-responsive genes such as Phosphate 1 (PHO1) and Phosphate transporter 1 (PHT1) under P deficiency (Fig. 4).

Since there is no soluble $\mathrm{P}$ in the $\mathrm{P}$-deficient nutrient solution, and cell wall can function as an important $P$ source when external $\mathrm{P}$ is not available (Yu et al. 2016; Zhu et al. 2015), the root and shoot cell wall P retention in both WT and myb103 were thus analyzed. Interestingly, more $\mathrm{P}$ was retained in the myb103 root cell wall than in WT (Fig. 5a and c), although no significant difference was found in the shoot cell wall $\mathrm{P}$ reutilization (Fig. $5 \mathrm{~b}$ and $\mathrm{d}$ ), suggesting that less $\mathrm{P}$ was reutilized in the myb103 root. Furthermore, as pectin dramatically contributes to cell wall P reutilization in rice (Zhu et al. 2015), we tested whether pectin content was affected in the myb103 mutant. As shown in Fig. 6, more P was adsorbed in the pectin fraction of the myb103 root cell wall under P deficiency while similar P was adsorbed under P sufficiency when compared to WT, indicating lower P-release potential in the pectin fraction of myb103 root cell walls (Fig. 6a). In consistent with this, a reduction of the pectin content was found in the myb103 root cell wall (Fig. 6b). Reduced pectin content in myb103 meant that there were fewer carboxyl groups available, which in turn led to reduced binding of cations like $\mathrm{Fe}^{3+}$, and thereby less $\mathrm{P}$ was released from the root cell wall in myb103.

\section{Disruption of MYB103 leads to less ethylene production} Our findings raises a question that how MYB103 interferes with the reutilization of the $\mathrm{P}$ from the cell wall.

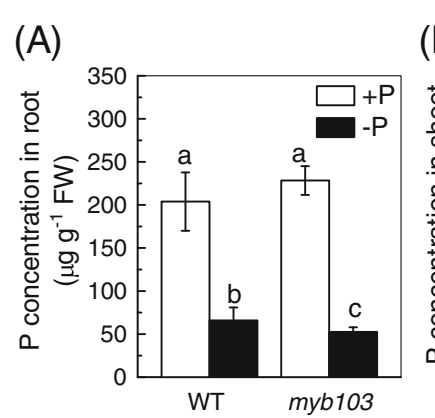

(B)

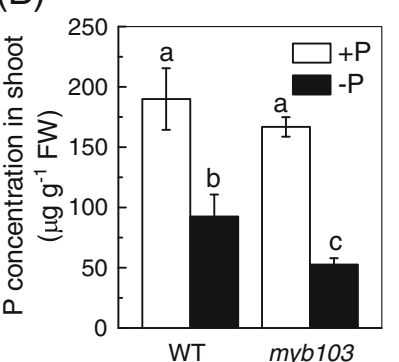

(C)

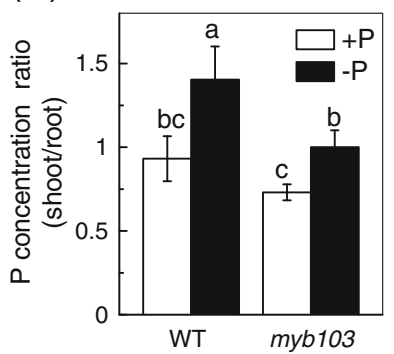

Fig. 3 Disruption of MYB103 affects root-to-shoot P translocation. WT and myb103 seedlings were grown under +P or -P conditions for $7 \mathrm{~d}$, root (a) and shoot (b) $\mathrm{P}$ concentration was measured. The ratio of shoot $\mathrm{P}$ concentration to root $\mathrm{P}$ concentration (c) was calculated. Values are means $\pm \mathrm{SD}, n=4$. Different letters represent a significant difference at $P<0.05$ 


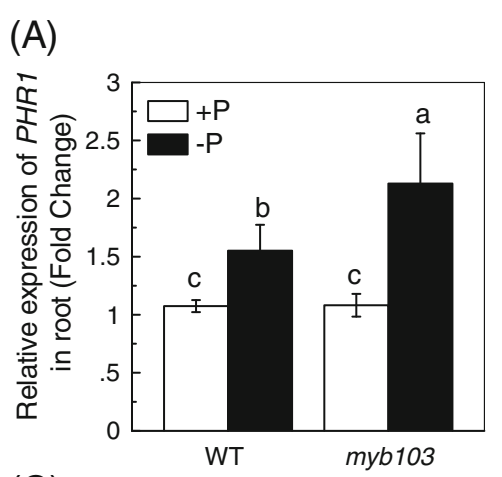

(B)
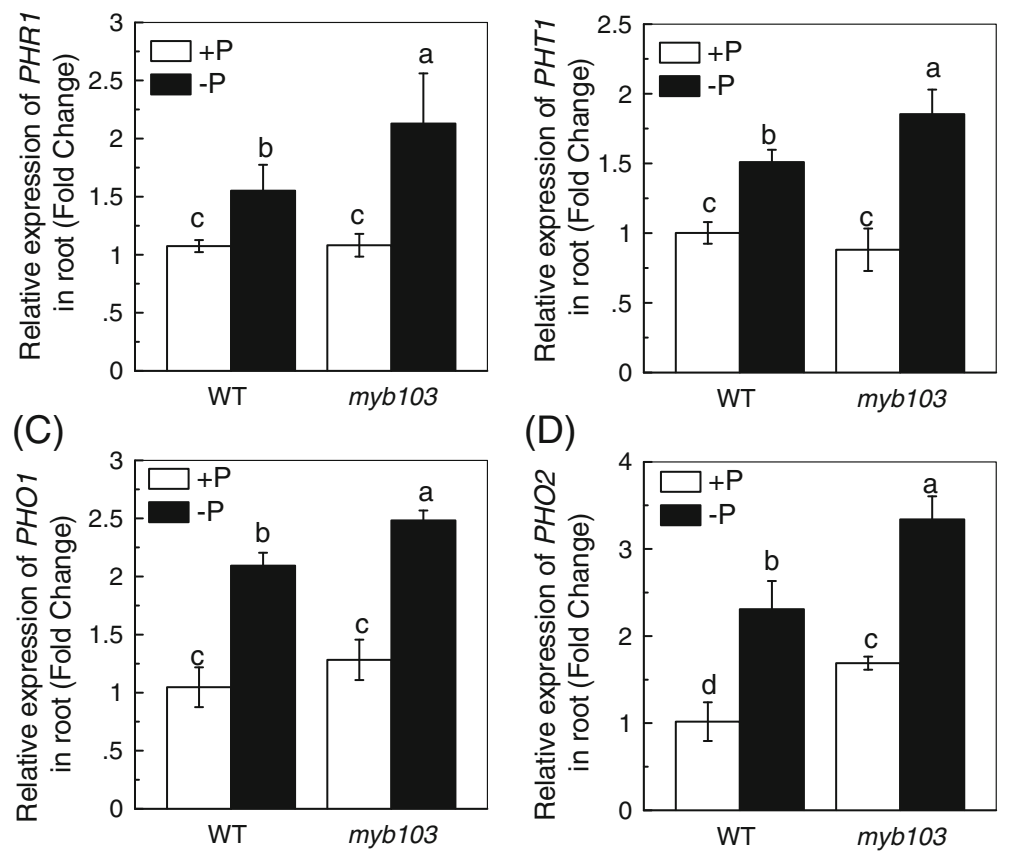

(D)

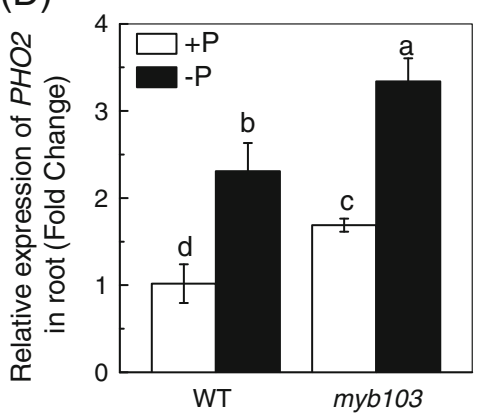

Fig. 4 Relative expression of genes involved in P acquisition and allocation in roots of WT and myb103. Seedlings were hydroponically treated with $+P$ or $-P$ solution for $7 d$, and roots were harvested for expression analysis
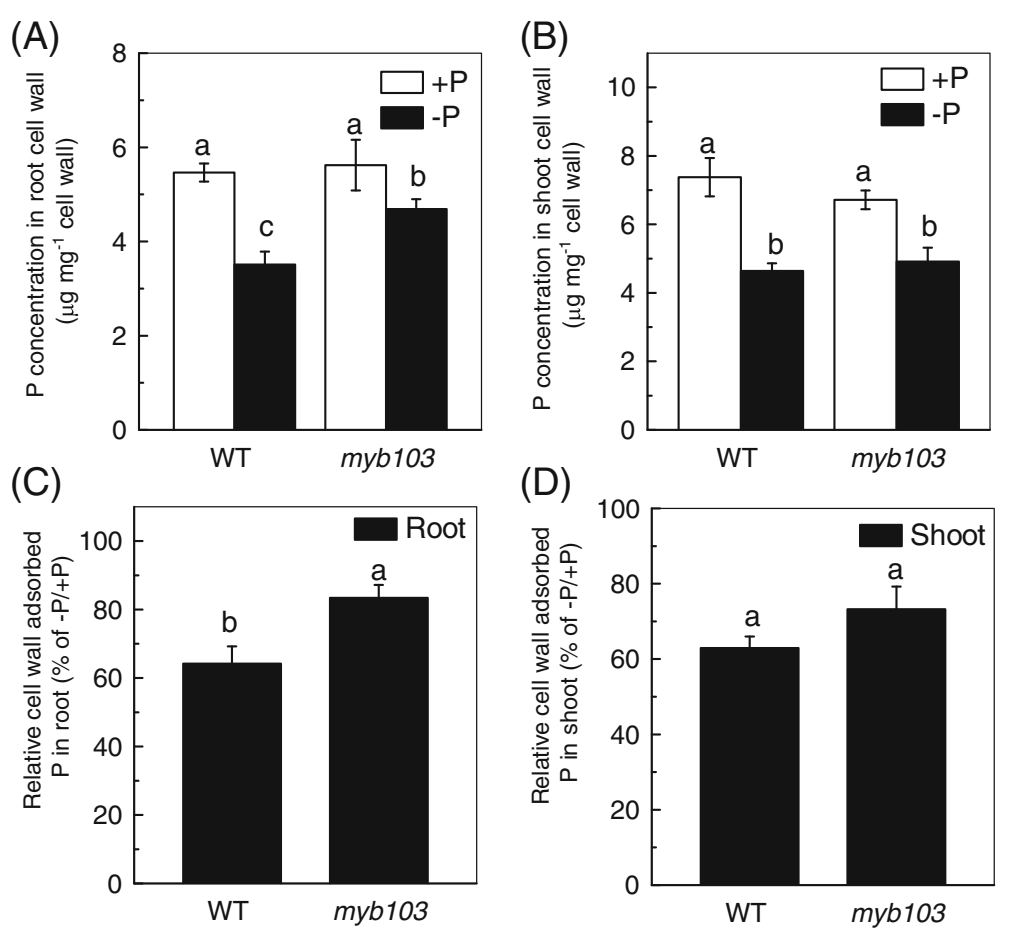

Fig. 5 Cell wall $P$ concentration. Seedlings were hydroponically treated with $+P$ or $-P$ solution for $7 d$, and the $P$ concentrations were measured in the root (a) and shoot (b) cell wall. The relative cell-wall-adsorbed P in the root (c) and shoot (d) was calculated from the P concentration in the root or shoot cell wall under $-\mathrm{P} /$ the $\mathrm{P}$ concentration in the root or shoot cell wall under $+\mathrm{P}$. Values are means $\pm S D, n=4$. Different letters on the bars indicate significant differences at $p<0.05$ 

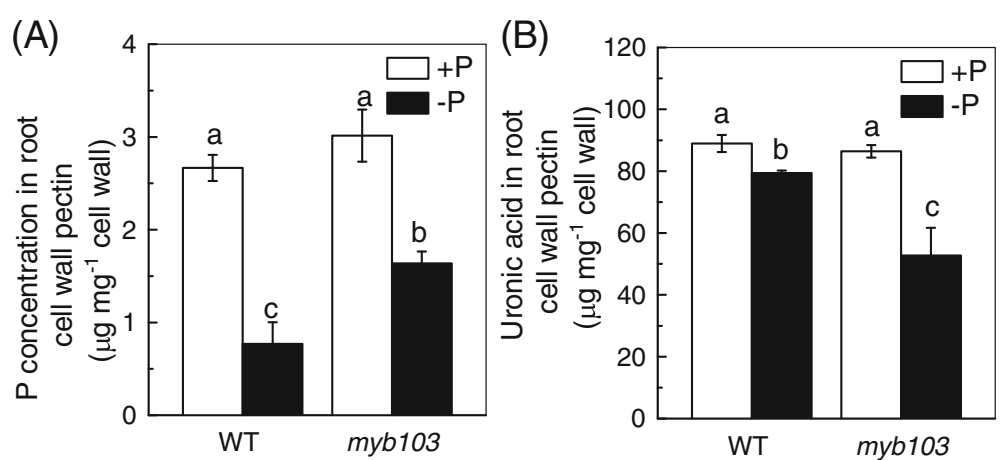

Fig. $6 \mathrm{P}$ concentration in cell wall pectin and pectin content. Seedlings were hydroponically treated with $+P$ or $-P$ solution for $7 d$, and cell wall materials extracted from roots were fractionated into pectin, then the $P$ concentration (a) and the uronic acid level (b) in the pectin were measured. Values are means $\pm S D, n=4$. Different letters on the bars indicate significant differences at $p<0.05$

Recently, ethylene has been shown to play pivotal roles in the reutilization of the cell wall $\mathrm{P}$ in Arabidopsis (Yu et al. 2016); therefore, we measured the production of ethylene in roots of WT and myb103. As shown in Fig. 7, less ethylene production was observed in myb103 roots under either P-deficient or P-replete conditions when compared to WT, indicating that ethylene could be an important player in the MYB103-regulated cell wall P reutilization.

\section{Discussion}

To cope with $\mathrm{P}$ limitation, plants deploy a series of physiological, biochemical, and molecular strategies such as modifying root architecture (Steingrobe 2001; Wang et al. 2010), secreting carboxylates and acid phosphatase

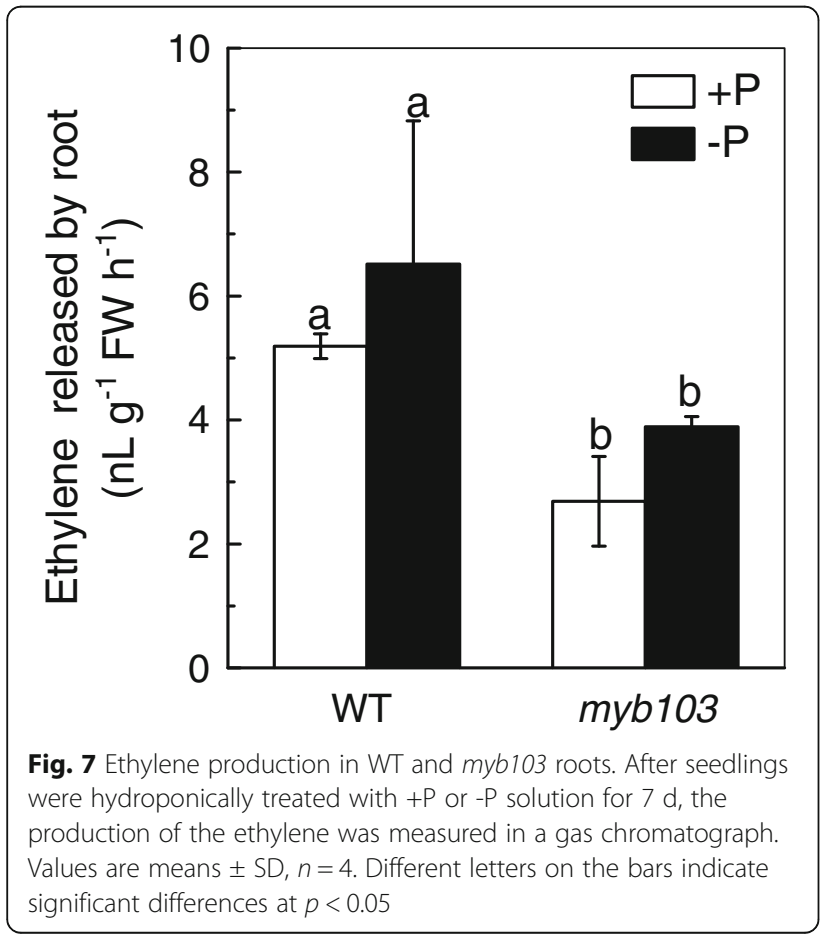

(Baldwin et al. 2001), elevating transcription of genes essential for P acquisition (Zhou et al. 2008), and enhancing the remobilization of the previously stored P (Kuga et al. 2008; Yu et al. 2016; Zhu et al. 2015). Transcriptional reprogramming, regulated by TFs, is the key to these adaptive responses to P deficiency (Gu et al. 2016; Wendrich et al. 2020), although many details remain to be unveiled. In this study, we show that a MYB TF, MYB103 is involved in $\mathrm{P}$ remobilization.

MYB TFs are implicated in a variety of plant's responses to environmental stimuli (Li et al. 2015; Stracke et al. 2001). For example, HOS10 (Zhu et al. 2005), MYB14 and MYB15 (Agarwal et al. 2006), MdMYB23 (An et al. 2018) and MdMYB308L (An et al. 2020) are involved in the modulation of cold stress response. MYB111 modulates salt stress (Li et al. 2019) while MYB12 is involved in response to nitrogen deficiency (Lea et al. 2007). PSR1 (Wykoff et al. 1999) and PHR1 (Rubio et al. 2001) are two well characterized R2R3 MYB transcription factors that have been implicated in the positive regulation of $\mathrm{P}$ stress responses. In addition, MYB62 plays an important role in the regulation of phosphate starvation responses via changes in gibberellic acid metabolism and signaling (Devaiah et al. 2009). In the present study, we found that MYB103, an R2R3 MYB $\mathrm{TF}$, was involved in the $\mathrm{P}$ deficiency response in Arabidopsis. The expression of MYB103 was induced under Pdeficient condition in Arabidopsis (Fig. 1), and disruption of MYB103 exhibited sensitivity to P deficiency (Fig. 2), due to lower levels of shoot and root soluble P (Fig. 3).

Cell wall, consisting of cellulose, hemicelluloses, pectin and other matrix polysaccharides, acts as an important $\mathrm{P}$ repository in rice and Arabidopsis (Cosgrove 2005; Yu et al. 2016; Zhu et al. 2015). Among them, only pectin has been shown to be involved in the $\mathrm{P}$ recycling under P-deficient condition, as the carboxyl groups in the cell wall pectin have strong affinity for cations, such as $\mathrm{Fe}^{3+}$, which lead to the release of the P (Gessa et al. 1997; Zhu 
et al. 2015). Our results once again confirmed the role of the P pool in cell wall pectin in WT under P deficiency, as myb103 was remarkably compromised in $\mathrm{P}$ reutilization when subjected to $\mathrm{P}$ deficiency (Fig. 5a and c), in company with the greatly reduced pectin content (Fig. 6b). As a result, more P was retained in the myb103 cell wall under Pdeficient condition (Fig. 5), thus less soluble P was available in myb103 roots and shoots, rendering it more sensitive to the P deficiency (Figs. 2 and 3). In agreement with this, the expression of $\mathrm{P}$ deficiency-responsive genes including Phosphate starvation response 1 (PHR1), PHO1, Phosphate 2 (PHO2) and PHT1, was higher in myb103 roots than in WT under P starvation (Fig. 4).

Then, how does MYB103 regulate the cell wall P reutilization? What are the downstream signals? Ethylene is known to act as a signal molecule that not only plays important roles in various physiological processes and plant growth, but also participates in the regulation of responses to different abiotic stresses (Johnson and Ecker 1998; Kazan 2015). While the role of ethylene in P deficiency in plants has been extensively examined (Nagarajan et al. 2011; Song and Liu 2015; Yu et al. 2016; Zhu et al. 2016), the regulators of ethylene production are largely elusive. MYB103 is presumably an important regulator of ethylene production. In the present study, we found that less ethylene was accumulated in roots of myb103, when compared with WT, irrespective of the P status (Fig. 7), indicating that less ethylene production was associated with increased sensitivity to P deficiency in myb103. However, it has yet to be investigated as to the molecular mechanism underlying regulation of ethylene production by MYB103.

\section{Conclusion}

Our results show that an R2R3 MYB TF, MYB103, is involved in the cell wall-based $\mathrm{P}$ reutilization under $\mathrm{P}$ deficiency through regulating ethylene production. Our study, thus, supports the importance of $\mathrm{P}$ remobilization from the plant cell wall under P deficiency, reveals an important regulator in this process, and furnishes new evidence on the essential role of ethylene during the important and prevalent macronutritional stress of $P$ deficiency.

\section{Supplementary information}

Supplementary information accompanies this paper at https://doi.org/10. 1186/s43014-020-00038-6.

Additional file $\mathbf{1}$ Table S1. List of Primers used in the current study.

Additional file 2 Figure S1. Identification of the myb103 mutant. (A) Schematic structure of the myb103 mutant carrying a single copy of the T-DNA insert in the third exon. The gray box represents exon while the black bold line represents intron. (B) Quantitative RT-PCR analysis of MYB103 expression in the roots of Arabidopsis. Values are means $\pm S D, n=4$. Different letters on the bars indicate significant differences at $p<0.05$.

\section{Abbreviations}

MYB TF: Myeloblastosis transcription factor; WT: Wildtype; P: Phosphorus; ICPMS: Inductively coupled plasma-mass spectrometry; NO: Nitric oxide

\section{Acknowledgements}

Not applicable.

\section{Authors' contributions}

$J L$ and FY conceived the work. FY and SW performed the experiments. FY, WZ, LY, HW analyzed the data. FY drafted the manuscript. JL and ZF revised the manuscript. All authors read and approved the final manuscript.

\section{Funding}

This research was funded in part by the National Key Research and Development Program (2016YFD0101702), the Key Research and Development Program of Jiangsu Province (BE2017379), "333 project" of Jiangsu Province (BRA2018379).

\section{Availability of data and materials}

Plant materials are available under request to the respective owner institutions. The datasets supporting the results of this article are included within the article and its additional files.

Ethics approval and consent to participate

Not Applicable.

\section{Consent for publication}

Not applicable.

\section{Competing interests}

The authors declare that they have no competing interests.

\section{Author details}

${ }^{1}$ Jiangsu Key Laboratory for Horticultural Crop Genetic Improvement, Institute of Vegetable Crops, Jiangsu Academy of Agricultural Sciences, Nanjing 210014, China. Boyce Thompson Institute, Cornell University, Ithaca, NY 14853, USA.

Received: 27 February 2020 Accepted: 29 September 2020 Published online: 28 October 2020

References

Agarwal, M., Hao, Y., Kapoor, A., Dong, C. H., Fujii, H., Zheng, X., \& Zhu, J. K. (2006) A R2R3 type MYB transcription factor is involved in the cold regulation of CBF genes and in acquired freezing tolerance. The Journal of Biological Chemistry, 281, 37636-37645.

An, J. P., Li, R., Qu, F. J., You, C. X., Wang, X. F., \& Hao, Y. J. (2018). R2R3-MYB transcription factor MdMYB23 is involved in the cold tolerance and proanthocyanidin accumulation in apple. The Plant Journal, 96, 562-577.

An, J. P., Wang, X. F., Zhang, X. W., Xu, H. F., Bi, S. Q., You, C. X., \& Hao, Y. J. (2020). An apple MYB transcription factor regulates cold tolerance and anthocyanin accumulation and undergoes MIEL1-mediated degradation. Plant Biotechnology Journal, 18, 337-353.

Baker, A., Ceasar, S. A., Palmer, A. J., Paterson, J. B., Qi, W., Muench, S. P., \& Baldwin, S. A. (2015). Replace, reuse, recycle: Improving the sustainable use of phosphorus by plants. Journal of Experimental Botany, 66, 3523-3540.

Baldwin, J. C., Karthikeyan, A. S., \& Raghothama, K. G. (2001). LEPS2, a phosphorus starvation-induced novel acid phosphatase from tomato. Plant Physiology, $125,728-737$.

Blumenkrantz, N., \& Asboe-Hansen, G. (1973). New method for quantitative determination of uronic acids. Analytical Biochemistry, 54, 484-489.

Cosgrove, D. J. (2005). Growth of the plant cell wall. Nature Review Molecular Cell Biology, 6, 850-861

Dai, X., Wang, Y., Yang, A., \& Zhang, W. H. (2012). OsMYB2P-1, an R2R3 MYB transcription factor, is involved in the regulation of phosphate-starvation responses and root architecture in rice. Plant Physiology, 159, 169-183.

Devaiah, B. N., Madhuvanthi, R., Karthikeyan, A. S., \& Raghothama, K. G. (2009). Phosphate starvation responses and gibberellic acid biosynthesis are regulated by the MYB62 transcription factor in Arabidopsis. Molecular Plant, 2, 43-58. 
Dubos, C., Stracke, R., Grotewold, E., Weisshaar, B., Martin, C., \& Lepiniec, L. (2010). MYB transcription factors in Arabidopsis. Trends in Plant Science, 15, 573-581.

Franco-Zorrilla, J. M., Gonzalez, E., Bustos, R., Linhares, F., Leyva, A., \& Paz-Ares, J. (2004). The transcriptional control of plant responses to phosphate limitation. Journal of Experimental Botany, 55, 285-293.

Gessa, C., Deiana, S., Premoli, A., \& Ciurli, A. (1997). Redox activity of caffeic acid towards iron(III) complexed in a polygalacturonate network. Plant and Soil, 190, 289-299.

Gu, M., Chen, A., Sun, S., \& Xu, G. (2016). Complex regulation of plant phosphate transporters and the gap between molecular mechanisms and practical application: What is missing? Molecular Plant, 9, 396-416.

Gutierrez-Alanis, D., Ojeda-Rivera, J. O., Yong-Villalobos, L., Cardenas-Torres, L., \& Herrera-Estrella, L. (2018). Adaptation to phosphate scarcity: Tips from Arabidopsis roots. Trends in Plant Science, 23, 721-730.

Hammond, J. P., Bennett, M. J., Bowen, H. C., Broadley, M. R., Eastwood, D. C., May, S. T., ... White, P. J. (2003). Changes in gene expression in Arabidopsis shoots during phosphate starvation and the potential for developing smart plants. Plant Physiology, 132, 578-596.

Hans, L., Michael, W. S., Michael, D. C., Stuart, J. P., \& Erik, J. V. (2006). Root structure and functioning for efficient acquisition of phosphorus: Matching morphological and physiological traits. Annals of Botany, 98, 693-713.

Johnson, P. R., \& Ecker, J. R. (1998). The ethylene gas signal transduction pathway: A molecular perspective. Annual Review of Genetics, 32, 227-254.

Kazan, K. (2015). Diverse roles of jasmonates and ethylene in abiotic stress tolerance. Trends in Plant Science, 20, 219-229.

Kuga, Y., Saito, K., Nayuki, K., Peterson, R. L., \& Saito, M. (2008). Ultrastructure of rapidly frozen and freeze-substituted germ tubes of an arbuscular mycorrhizal fungus and localization of polyphosphate. New Phytologist, 178, 189-200.

Lauer, M. J., Blevins, D. G., \& Sierzputowska-Gracz, H. (1989). ${ }^{31}$ P-nuclear magnetic resonance determination of phosphate compartmentation in leaves of reproductive soybeans (Glycine max L.) as affected by phosphate nutrition. Plant Physiology, 89, 1331-1336.

Lea, U. S., Slimestad, R., Smedvig, P., \& Lillo, C. (2007). Nitrogen deficiency enhances expression of specific MYB and bHLH transcription factors and accumulation of end products in the flavonoid pathway. Planta, 225, 12451253.

Li, B. Z., Fan, R. N., Guo, S. Y., Wang, P. T., Zhu, X. H., Fan, Y. T., ... Song, C. P. (2019). The Arabidopsis MYB transcription factor, MYB111 modulates salt responses by regulating flavonoid biosynthesis. Environmental and Experimental Botany, 166, 103807.

Li, C., Ng, C. K. Y., \& Fan, L. M. (2015). MYB transcription factors, active players in abiotic stress signaling. Environmental and Experimental Botany, 114, 80-91.

Liang, C., Wang, J., Zhao, J., Tian, J., \& Liao, H. (2014). Control of phosphate homeostasis through gene regulation in crops. Current Opinion in Plant Biology, 21, 59-66.

Livak, K. J., \& Schmittgen, T. D. (2001). Analysis of relative gene expression data using real-time quantitative PCR and the $2^{-\Delta \Delta C T}$ method. Methods, 25, 402408.

Lopez-Arredondo, D. L., Leyva-González, M. A., González-Morales, S. I., LópezBucio, J., \& Herrera-Estrella, L. (2014). Phosphate nutrition: Improving lowphosphate tolerance in crops. Annual Review of Plant Biology, 65, 95-123.

Mimura, T. (1995). Homeostasis and transport of inorganic phosphate in plants. Plant \& Cell Physiology, 36, 1-7.

Morcuende, R., Bari, R., Gibon, Y., Zheng, W., Pant, B. D., Blasing, O., ... Scheible, W. R. (2007). Genome-wide reprogramming of metabolism and regulatory networks of Arabidopsis in response to phosphorus. Plant, Cell \& Environment, 30, 85-112.

Nagarajan, V. K., Jain, A., Poling, M. D., Lewis, A. J., Raghothama, K. G., \& Smith, A. P. (2011). Arabidopsis Pht1;5 mobilizes phosphate between source and sink organs and influences the interaction between phosphate homeostasis and ethylene signaling. Plant Physiology, 156, 1149-1163.

Palapol, Y., Ketsa, S., Lin-Wang, K., Ferguson, I. B., \& Allan, A. C. (2009). A MYB transcription factor regulates anthocyanin biosynthesis in mangosteen (Garcinia mangostana L.) fruit during ripening. Planta, 229, 1323-1334.

Rubio, V., Linhares, F., Solano, R., Martin, A. C., Iglesias, J., Leyva, A., \& Paz-Ares, J. (2001). A conserved MYB transcription factor involved in phosphate starvation signaling both in vascular plants and in unicellular algae. Genes \& Development, 15, 2122-2133.

Schachtman, D. P., Reid, R. J., \& Ayling, S. M. (1998). Phosphorus uptake by plants: From soil to cell. Plant Physiology, 116, 447-453.
Schellingen, K., Van Der Straeten, D., Vandenbussche, F., Prinsen, E., Remans, T., Vangronsveld, J., \& Cuypers, A. (2014). Cadmium-induced ethylene production and responses in Arabidopsis thaliana rely on ACS2 and ACS6 gene expression. BMC Plant Biology, 14, 214.

Song, L., \& Liu, D. (2015). Ethylene and plant responses to phosphate deficiency. Frontiers in Plant Science, 6, 796.

Steingrobe, B. (2001). Root renewal of sugar beet as a mechanism of $P$ uptake efficiency. Journal of Plant Nutrition and Soil Science, 164, 533-539.

Stracke, R., Werber, M., \& Weisshaar, B. (2001). The R2R3-MYB gene family in Arabidopsis thaliana. Current Opinion in Plant Biology, 4, 447-456.

Su, T., Xu, Q., Zhang, F. C., Chen, Y., Li, L. Q., Wu, W. H., \& Chen, Y. F. (2015). WRKY42 modulates phosphate homeostasis through regulating phosphate translocation and acquisition in Arabidopsis. Plant Physiology, 167, 1579-1591.

Tian, Y., Zhang, H., Pan, X., Chen, X., Zhang, Z., Lu, X., \& Huang, R. (2011). Overexpression of ethylene response factor TERF2 confers cold tolerance in rice seedlings. Transgenic Research, 20, 857-866.

Vance, C. P., Uhde-Stone, C., \& Allan, D. L. (2003). Phosphorus acquisition and use: Critical adaptations by plants for securing a nonrenewable resource. New Phytologist, 157, 423-447.

Wang, B. L., Tang, X. Y., Cheng, L. Y., Zhang, A. Z., Zhang, W. H., Zhang, F. S., Shen, J. B. (2010). Nitric oxide is involved in phosphorus deficiency-induced clusterroot development and citrate exudation in white lupin. New Phytologist, 187, 1112-1123.

Wang, S., Yu, F., Tang, J., Zhang, W., Wang, H., Yu, L., \& Li, J. (2018). Boron promotes phosphate remobilization in Arabidopsis thaliana and Brassica oleracea under phosphate deficiency. Plant and Soil, 431, 191-202.

Wendrich, J. R., Yang, B., Vandamme, N., Verstaen, K., Smet, W., Van de Velde, C., De Rybel, B. (2020). Vascular transcription factors guide plant epidermal responses to limiting phosphate conditions. Science, eaay4970.

Wu, J., Wang, C., Zheng, L., Wang, L., Chen, Y., Whelan, J., \& Shou, H. (2011). Ethylene is involved in the regulation of iron homeostasis by regulating the expression of iron-acquisition-related genes in Oryza sativa. Journal of Experimental Botany, 62, 667-674.

Wykoff, D. D., Grossman, A. R., Weeks, D. P., Usuda, H., \& Shimogawara, K. (1999) Psr1, a nuclear localized protein that regulates phosphorus metabolism in Chlamydomonas. Proceedings of the National Academy of Sciences USA, 96, 15336-15341.

Yu, F. W., Zhu, X. F., Li, G. J., Kronzucker, H. J., \& Shi, W. M. (2016). The chloroplast protease AMOS1/EGY1 affects phosphate homeostasis under phosphate stress. Plant Physiology, 172, 1200-1208.

Zhong, H., \& Lauchli, A. (1993). Changes of cell wall composition and polymer size in primary roots of cotton seedlings under high salinity. Journal of Experimental Botany, 44, 773-778.

Zhou, J., Jiao, F., Wu, Z., Li, Y., Wang, X., He, X., ... Wu, P. (2008). OsPHR2 is involved in phosphate-starvation signaling and excessive phosphate accumulation in shoots of plants. Plant Physiology, 146, 1673-1686.

Zhu, J., Verslues, P. E., Zheng, X., Lee, B. H., Zhan, X., Manabe, Y., ... Bressan, R. A. (2005). HOS10 encodes an R2R3-type MYB transcription factor essential for cold acclimation in plants. Proceedings of the National Academy of Sciences USA, 102, 9966-9971.

Zhu, X. F., Wang, Z. W., Wan, J. X., Sun, Y., Wu, Y. R., Li, G. X., ... Zheng, S. J. (2015). Pectin enhances rice (Oryza sativa) root phosphorus remobilization. Journal of Experimental Botany, 66, 1017-1024.

Zhu, X. F., Zhu, C. Q., Zhao, X. S., Zheng, S. J., \& Shen, R. F. (2016). Ethylene is involved in root phosphorus remobilization in rice (Oryza sativa) by regulating cell-wall pectin and enhancing phosphate translocation to shoots. Annals of Botany, 118, 645-653.

\section{Publisher's Note}

Springer Nature remains neutral with regard to jurisdictional claims in published maps and institutional affiliations. 